\title{
Erratum to: Local Perceptions of MPB Infestation, Forest Management, and Connection to National Forests in Colorado and Wyoming
}

Pavlina McGrady $^{1} \cdot$ Stuart Cottrell $^{1} \cdot$ Jessica Clement $^{2} \cdot$ Jana Raadik Cottrell $^{1}$.

Michael Czaja ${ }^{1}$

Published online: 17 February 2016

(C) Springer Science+Business Media New York 2016

Erratum to: Hum Ecol

DOI: 10.1007/s10745-015-9803-8

In the original publication, the author name "Jessica Clement" was incorrectly written as "Clement Jessica". The correct author name is given above. The original version was corrected.

The online version of the original article can be found at http://dx.doi.org/ 10.1007/s10745-015-9803-8.

Stuart Cottrell

stuart.cottrell@colostate.edu

1 Department of Human Dimensions of Natural Resources, Colorado State University, Fort Collins, CO, USA

2 Ruckelshaus Institute of Environment and Natural Resources, University of Wyoming, HaubSchool, Laramie, WY, USA 